\title{
Knowledge of pregnant women on the factors that influence anaemia in pregnancy in a rural farming district of the Western Region of Ghana
}

\author{
Kennedy D. Konlan', Roberta M. Amoah ${ }^{2 *}$, Joel A. Saah², Juliana A. Abdulai ${ }^{3}$, \\ Iddrisu Mohammed ${ }^{4}$, Kennedy Dodam Konlan ${ }^{5}$, Abdul Razak Doat ${ }^{6}$
}

\begin{abstract}
${ }^{1}$ Department of Public Health Nursing, School of Nursing and Midwifery, University of Health and Allied Sciences, Ho, Volta Region, Ghana

${ }^{2}$ Department of Public Health, School of Allied Sciences, University for Development Studies, Tamale Northern Region, Ghana

${ }^{3}$ Department of Surgery, Tamale Teaching Hospital, Tamale, Northern Region, Ghana

${ }^{4}$ Nurses' and Midwives' Training College, Tamale. Tamale, Northern Region, Ghana

${ }^{5}$ Department of Adult Health, School of Nursing and Midwifery, University of Ghana, Legon, Greater Accra Region, Ghana

${ }^{6}$ Tehran University of Medical Sciences- School of Nursing and Midwifery, Tehran, Iran. Nursing and Midwifery Training College, Tamale, Northern Region, Ghana
\end{abstract}

Received: 09 April 2020

Accepted: 01 May 2020

*Correspondence:

Dr. Roberta M. Amoah,

E-mail: mensima3199efua@gmail.com

Copyright: (C) the author(s), publisher and licensee Medip Academy. This is an open-access article distributed under the terms of the Creative Commons Attribution Non-Commercial License, which permits unrestricted non-commercial use, distribution, and reproduction in any medium, provided the original work is properly cited.

\section{ABSTRACT}

Background: The presence of anaemia in pregnancy is one of the serious public health concerns across the globe especially in developing countries like Ghana. This study assessed pregnant women's knowledge on factors influencing aneamia in pregnancy in a low-income district of Ghana.

Methods: A quantitative descriptive cross-sectional study. Data was collected using a pretested questionnaire. 112 pregnant women seeking antenatal care were recruited using systematic sampling technique in the Wassa East district of Ghana. Data were cleaned and entered into SPSS version 22 and analysed into descriptive statistics.

Results: Majority of participants; $72.3 \%$ did not know the causes of anaemia in pregnancy. Pregnant women $(27.7 \%)$ indicated nutritional deficiency as a common cause of anaemia; $18.7 \%$ of them could identify appropriately at least one sign of anaemia in pregnancy with $28 \%$ asserting that pregnancy-related anaemia can affect labour, despite $72 \%$ indicating that anaemia could cause maternal mortality. The reasons for irregular ANC attendance included; perceived non importance of ANC (18.8\%), financial difficulties (17.9\%), health facility inaccessibility $(18.8 \%)$ and time constraints $(44.5 \%)$. There was a strong association between knowledge level on the cause of anaemia in pregnancy and the educational level of pregnant women $(\mathrm{p}=0.005$ chi square $=50.289)$.

Conclusions: Lack of knowledge on the importance of antenatal care and financial constraints were among the reasons leading to a surge in anaemia amongst pregnant women in the district. Health providers should incorporate services which enable pregnant women to access valuable information on anaemia prevention in pregnancy.

Keywords: Anaemia, Deficiency, Factors, Pregnancy, Rural community

\section{INTRODUCTION}

Anaemia remains a major health concern to world health authorities as dozens of pregnant women suffer from the condition before they put to birth. About $56 \%$ of pregnant women in developing countries and $18 \%$ in developed countries are anaemic, and in Africa, the estimated prevalence in pregnant women is 50-60\%. Anaemia 
affects nearly half of all pregnant women in the world; $52 \%$ in developing countries compared with $23 \%$ in the developed world. $^{2}$ In developing countries, the prevalence of anaemia in pregnant women is commonly in the range of $40-60 \% .^{3}$ The global prevalence among pregnant women was said to have increased to $46.3 \%$ in 2011 with 9.2 million cases in Africa alone. ${ }^{3}$ Almost half of the pregnant mothers globally present haematological values indicative of anaemia. ${ }^{4}$ People at risk of anaemia are infants, preschool children, adolescents and women of childbearing age, particularly pregnant women. ${ }^{5,6}$ The World Health Organization (2016) defined anaemia in pregnancy as the haemoglobin $(\mathrm{Hb})$ concentration of less than $11 \mathrm{~g} / \mathrm{dl}^{3}$. Anaemia is said to be of public health significance or problem if population studies find the anaemia prevalence of $5.0 \%$ or higher as the prevalence of anaemia of $\geq 40 \%$ in a population is classified as a severe public health problem.

The causes of anaemia during pregnancy in developing countries are multi-factorial; including micronutrient deficiencies of iron, folate, vitamins A and B12 as well as anaemia due to parasitic infections such as malaria and hookworm or chronic infections like TB and HIV. ${ }^{8,9}$ Contributions of each of these factors that cause anaemia during pregnancy vary due to geographical location, dietary practices and season. ${ }^{10}$ Nonetheless, in SubSaharan Africa, inadequate intake of diets rich in iron is reported to be the leading cause of anaemia among pregnant women. ${ }^{10,11}$ The risk factors known to contribute to anaemia include low income, large family size, inadequate nutrition, infection, sickle cell disease, blood pressure and gestational age. ${ }^{10}$ Anaemia exposes both the mother and the unborn baby to serious risks which include; low birth weight, fetal distress, premature delivery, and maternal mortality. ${ }^{6,9,11,12}$ Sub-Saharan Africa is the most affected with an estimation of 17.2 million cases among pregnant women, representing $30 \%$ of global cases. ${ }^{10,11}$

The prevalence of anaemia in Ghana is quite pervasive. Four out of every ten women in their reproductive age in Ghana suffers from some form of anaemia. ${ }^{13}$ Although the country has improved in reducing the prevalence of anaemia from 59\% in 2008 to $42 \%$ in 2014 , anaemia still remains a serious public health concern in Ghana. ${ }^{13}$ Interventions adopted by the Ghana Health Service (GHS) to prevent anaemia in pregnancy includes the free supply of iron/folate to pregnant women, free routine $\mathrm{Hb}$ levels check for pregnant women at ANC registration and at 36 weeks of pregnancy, free Intermittent Preventive Treatment administration using SulphadoxinePyrimethamine (IPTp-SP) and free provision of Long Lasting Insecticide Net (LLIN). Annual health reports in Wassa East District of Ghana the prevalence of anaemia among pregnant women for 2016 to be $50.5 \%$ which was above the national average. A three-year trend of the annual review indicates that anaemia in pregnancy still leads to maternal death in Wassa East District. Even though protective foods are cultivated in the district, iron deficiency anaemia is still on the ascendency among pregnant women. Data from the district health information management system (2016), reveals that anaemia prevalence among pregnant women in Wassa East increased from $48.8 \%$ in 2015 to $50.5 \%$ in 2016 which shows an increase of $1.7 \%$. To be able to reduce this menace of high prevalence of anaemia among pregnant women, the practices of these women remain central. This practice is in tandem to the women's level of knowledge. The knowledge women have on preventive measures will directly relate to the practices they do in preventing the disease.

This study assessed pregnant women's knowledge on the factors that influence aneamia in pregnancy in a lowincome rural farming district of the western region of Ghana.

\section{METHODS}

\section{Study design}

A descriptive cross-sectional study that collected data from pregnant women at a point in time and no follow up was required. The study described the factors that influence anaemiain pregnancy in a rural farming community in Ghana.

\section{Study setting}

The study was conducted in Wassa East District which is located at the South-Eastern end of the Western Region. It is bounded to the North East and South East by the Twifo Hemang Lower Denkyira, Twifo Atti-Morkwa and Komenda Edina Eguafo Abrem Districts respectively; all in the Central Region. The district is bounded on the North West by the Prestea Huni-Valley District. In the south, it is bounded by, Mpohor and Shama Districts (GSS, 2010). The district capital is Daboase, which is 6.7 $\mathrm{km}$ off the Cape Coast - Takoradi main road. The common occupation of the people includes farming, hunting and few engaging in trading and mining. The District has a projected population of 89,525 with four (4) administrative health sub-districts: namely Daboase, Ateiku, Atobiase and SekyereKrobo. There is a total of 29 health facilities in the District with 24 of them being government: 18 CHPS, 2 Health centers, 4 community clinics, 1 hospital and 2 maternity homes, 1 mission hospital and 1 industrial clinic.

\section{Study population}

The target population for this study was women of reproductive age in the Wassa East District of the western region - Ghana. The study population was pregnant women who attended antenatal services in the Daboase and Ateiku health centers. These two health facilities were chosen using simple probability sampling of blind picking each facility from a collected list of the facilities within the district. Only pregnant women who were 
above 28 weeks of pregnancy were recruited for the study. This cadre of respondents had a high chance of having an experience of taking iron supplementation in pregnancy as well as intermittent preventive treatment of malaria and the free distribution of insecticide-treated bed nets- a policy of the Ghana Health Service aimed at prevention of anaemia and other related health problems in pregnancy.

\section{Sample and sampling technique}

A total of 112 pregnant women was selected using a systematic sampling method determined by using the single proportion formula. For a period of two weeks, pregnant women above 28 weeks seeking antenatal services at the study sites were calculated and a sample fraction extrapolated. Using a sample fraction by 4, every fourth person who was above 28 weeks gestation was recruited.

$\mathrm{n}=\frac{(Z)^{2} \times P(1-P)}{(e)^{2}}$

Where $\mathrm{n}$ is the sample size, $\mathrm{Z}$ is the margin of error for 95\% confidence level (using the $\mathrm{T}$-distribution gives $\mathrm{z}=1.96$.), e is the standard error,], $P$ the probability of finding a woman 28 weeks gestation in the target population (Where $\mathrm{p}=0.07$ ).

\section{Data collection and analysis}

A pretested research questionnaire was used for data collection. The questionnaire was put into four sections: section A comprised biographic data and last Hgb test results, section $\mathrm{B}$ knowledge on anaemia, section $\mathrm{C}$ attitude towards anaemia prevention and section D factors influencing the perception of pregnant women on anaemia.

The research questionnaire was pretested in the Ahmadiyya hospital. A health facility located around the same district and had similar demographic characteristics as the study site. The tool was revised severally to ensure validity and reliability. The final tool had a Cronbach Alpha coefficient of 0.78 .

Respondents who could not read and write were assisted by trained research assistants to complete the questionnaire and for those who could read and write a self-administration was done. Research assistants prior to the commencement of data collection received a two-day intensive training on the tool and data collection method.

The data collected each day was checked for completeness and appropriateness of responses. Data collected were coded, sorted, entered and saved using the statistical package for social science (SPSS) version 22.0. Numerical data were analyzed using descriptive statistics. Cross-tabulation analysis was performed to determine the association between categorical variables, and $p$ value of less than 0.05 significance level was considered statistically significant.

\section{Ethical considerations}

The research was reviewed by the University of Health and Allied Sciences' institute of health research [UHASREC A.2 (132) 18-19]. Permission was also obtained from health service administrators and nurse managers of the two study sites prior to the data collection. Respondents individually gave consent before they were enrolled into the study.

The procedure of the research was explained to each respondent in English or the local dialects. Respondents were given adequate time to make an informed decision to participate. Respondents also had an option to withdraw from the study by alerting the interviewer if they so wish.

\section{RESULTS}

Age distribution of respondents from Table 1 showed $13.4 \%$ were between the ages of $15-20$ years, $46.4 \%$ were between $21-30$ years, $31.3 \%$ were between $31-40$ years and the remaining $8.9 \%$ were above 40 years.

Table 1: Demographic characteristics of study respondents.

\begin{tabular}{|c|c|c|c|}
\hline Variables & Parameter & $\begin{array}{l}\text { Frequency } \\
\text { (f) }\end{array}$ & $\%$ \\
\hline \multirow{4}{*}{$\begin{array}{l}\text { Age } \\
\text { distribution }\end{array}$} & $15-20$ years & 15 & $13.4 \%$ \\
\hline & 21-30 years & 52 & $46.4 \%$ \\
\hline & $31-40$ years & 35 & $31.3 \%$ \\
\hline & above 40 years & 10 & $8.9 \%$ \\
\hline \multirow{4}{*}{$\begin{array}{l}\text { Educational } \\
\text { level }\end{array}$} & $\begin{array}{l}\text { No formal } \\
\text { education }\end{array}$ & 61 & $54.5 \%$ \\
\hline & Basic school & 31 & $27.7 \%$ \\
\hline & $\begin{array}{l}\text { Secondary } \\
\text { school }\end{array}$ & 10 & $8.9 \%$ \\
\hline & Tertiary & 10 & $8.9 \%$ \\
\hline \multirow{4}{*}{ Occupation } & Farmers & 21 & $18.8 \%$ \\
\hline & Civil servants & 14 & $12.5 \%$ \\
\hline & Traders & 42 & $37.4 \%$ \\
\hline & Unemployed & 35 & $31.3 \%$ \\
\hline \multirow{3}{*}{ Religion } & Christians & 72 & $64.3 \%$ \\
\hline & Muslims & 10 & $8.9 \%$ \\
\hline & Traditionalists & 30 & $26.9 \%$ \\
\hline \multirow{2}{*}{$\begin{array}{l}\text { Marital } \\
\text { status }\end{array}$} & Married & 72 & $64.3 \%$ \\
\hline & Unmarried & 40 & $35.7 \%$ \\
\hline \multirow{3}{*}{$\begin{array}{l}\text { Number of } \\
\text { children }\end{array}$} & $0-2$ & 40 & $35.7 \%$ \\
\hline & $3-4$ & 52 & $46.4 \%$ \\
\hline & $5-6$ & 20 & $17.9 \%$ \\
\hline \multirow{4}{*}{$\begin{array}{l}\text { Last Hgb } \\
\text { test results } \\
\text { of pregnant } \\
\text { women }\end{array}$} & Less than 4 & 14 & $12.5 \%$ \\
\hline & 4.1 to 7.5 & 36 & $32.1 \%$ \\
\hline & 7.6 to 11 & 49 & $43 \%$ \\
\hline & More than 11 & 13 & $11.6 \%$ \\
\hline
\end{tabular}


Also, $54.5 \%$ had no formal education while $27.7 \%$ had basic education and $8.9 \%$ had tertiary education. A majority $(58.3 \%)$ was engaged in trading as $8.9 \%$ were civil servants. Farmers constituted $17.9 \%$ with $35.7 \%$ being unemployed. Christians were 64.3\%, Muslims $8.9 \%$ and $26.9 \%$ belonged to the Africa traditional religion. More than half $(64.3 \%)$ of the respondents were married while $46.4 \%$ had between $3-4$ children.

Pregnant women $(27.7 \%)$ indicated nutritional deficiency is a common cause of anaemia in pregnancy as $72.3 \%$ did not know the causes of anaemia. Also, $27.7 \%$ indicated worm infestations can cause anaemia.

Signs associated with anaemia included white nail beds $(8.9 \%)$, conjunctival pallor $(17.9 \%)$, while $54.5 \%$ of the respondents could not identify any sign of anaemia.

Again, few pregnant women (18.7\%) could identify appropriately at least one sign of anaemia in pregnancy as of pregnant women $(28 \%)$ indicated anaemia could affect labour, $(36 \%)$ were not certain, while $36 \%$ disagreed on that assertion. Most (72\%) of respondents indicated anaemia could be the cause of maternal mortality.

The results for the last Hbg checked for pregnant women were determined from the maternal health record cards of each participant. The results showed $\mathrm{Hgb}$ of less than 4 (12.5\%), 4.1 to $7.5(32.1 \%), 7.6$ to $11.0(43 \%)$ and more than $11.0(11.6 \%)$.

Pregnant women $(37 \%)$ indicated they did not attend ANC regularly as recommended by health professionals. Of the $63 \%$ of pregnant women who attended antenatal regularly, $35.7 \%$ had their booking visit in the first trimester, $17.9 \%$ within the fourth to the sixth month, $14.1 \%$ visited for the first time after 7 months gestation.
Some $(46 \%)$ did not take anti-anaemia medications usually prescribed at the antenatal clinic. A majority $(72 \%)$ of pregnant women usually sleeps under insecticide treated bed nets as $37.0 \%$ indicated they did not usually take the medication given to them at the antenatal clinic to treat malaria. On their dietary pattern $54.5 \%$ feed based on recommendations of health professionals.

The reasons for irregular ANC attendance included, perceived antenatal not to be important $(18.8 \%)$, financial difficulties $(17.9 \%)$, the facility was far from their home (18.8\%) and do not have enough time to spend at the clinic (44.5\%).

The reasons for non-adherence to dietary advice from health care professionals included lack of money (45.5\%), ascribe less importance to dietary recommendations (8.9\%) and lack of access to recommended food items $(9.8 \%)$. The reasons for none use of preventive anti-malarial prophylaxis included lack of awareness (18.7\%) and preference of herbal treatment methods $(17.8 \%)$.

There was a strong association between knowledge level on the cause of anaemia in pregnancy and the educational level of pregnant women as seen in Table 2 ( $\mathrm{p}=0.005 \mathrm{chi}$ square $=50.289$ ).

All pregnant women with tertiary education directly associated nutrition with the cause of anaemia while pregnant women who had no formal education or basic education did not associate nutrition to the cause of malaria. There was a strong relationship between knowledge level and antenatal attendance $(\mathrm{p}=0.005$ chi square $=82.89$ ) as evidenced by the chi-square test with a degree of freedom of 3 and a $p<0.005$.

Table 2: Association between demographic variables and knowledge of pregnant on anaemia.

\begin{tabular}{|c|c|c|c|c|}
\hline & $\begin{array}{l}\text { Socio-demographic } \\
\text { variables }\end{array}$ & \multicolumn{2}{|c|}{$\begin{array}{l}\text { Knowledge of nutritional causes of } \\
\text { anemia }\end{array}$} & chi-square \\
\hline & & Yes & Don't know & \multirow{5}{*}{$\begin{array}{l}\text { chi square }=50.289 \\
d f=3 \\
p=0.000\end{array}$} \\
\hline \multirow{4}{*}{$\begin{array}{l}\text { Educational } \\
\text { status }\end{array}$} & None & $0(0.0 \%)$ & $20(100 \%)$ & \\
\hline & Basic & $0(0.0 \%)$ & $31(100 \%)$ & \\
\hline & Secondary & $21(41.2 \%)$ & $30(58.8 \%)$ & \\
\hline & Tertiary & $10(100 \%)$ & $0(0.0 \%)$ & \\
\hline \multicolumn{5}{|c|}{ Regularity of ANC attendance in current pregnancy } \\
\hline & & Yes & No & \\
\hline \multirow{4}{*}{$\begin{array}{l}\text { Educational } \\
\text { status }\end{array}$} & None & $0(0.0 \%)$ & $20(100 \%)$ & \multirow{4}{*}{$\begin{array}{l}\text { chi square }=82.809 \\
\mathrm{df}=3 \\
\mathrm{p}=0.000\end{array}$} \\
\hline & Basic & $10(32.2 \%)$ & $21(67.8 \%)$ & \\
\hline & Secondary & $51(100 \%)$ & $0(0.0 \%)$ & \\
\hline & Tertiary & $10(100 \%)$ & $0(0.0 \%)$ & \\
\hline \multirow{3}{*}{ Ethnicity } & Ewe & $41(56.9 \%)$ & $31(43.1 \%)$ & \multirow{3}{*}{$\begin{array}{l}\text { chi square }=14.385 \\
d f=2 \\
p=0.001\end{array}$} \\
\hline & Akan & $20(100 \%)$ & $0(0.0 \%)$ & \\
\hline & Other & $10(50 \%)$ & $10(50 \%)$ & \\
\hline
\end{tabular}




\section{DISCUSSION}

This study mainly assessed factors accounting for the high prevalence of anaemia among pregnant women in the Wassa East District of the western region of Ghana. Inadequate knowledge was shown when pregnant women $(72.3 \%)$ could not identify at least one cause of anaemia in pregnancy. The significance of women's knowledge of animals is emphasized in a cross-sectional hospital-based study in India, which reported that lower knowledge about anaemia in pregnant women increased risk 'five times' and the worse practice about prevention of anaemia in pregnant women increased anaemia risk 'six times. ${ }^{14}$ Few pregnant women $(18.7 \%)$ could identify appropriately at least one sign of anaemia in pregnancy. This makes pregnant women vulnerable to the consequences of anaemia in pregnancy as early detection by the woman could not be guaranteed. Similar results on awareness of anaemia among caregivers of pregnant women showed that $70 \%$ of the women did not know the grave consequences of anaemia in pregnancy, signs and symptoms, although they were able to identify some foods with iron sources. ${ }^{15}$ Only $36 \%$ of pregnant women stated appropriately that anaemia could have a dire consequence on their pregnancy. The inability of pregnant women to directly associate anaemia to fatal consequences during pregnancy is not an incentive for them to take measures towards living a healthy life in pregnancy. In a study in Kiboga District in Uganda on knowledge of pregnant women on anaemia only $45.7 \%$ of respondents (pregnant women) were aware of some negative consequences of anaemia during pregnancy to both the mother and the child. ${ }^{9}$ Noteworthy, the Health Management Team in the Wassa district needs to review and implement a holistic policy that will address the gap in knowledge on anaemia during pregnancy.

Also, in this study, $54.5 \%$ of pregnant women could not identify any sign or symptom of anaemia in pregnancy, though education on pregnancy and anaemia is one of the mandatory education topics delivered to pregnant women when they visit the ANC. Though pregnant women receive some form of education at the ANC, the mode through which the education is conducted might be an impeding factor. Most times health education are delivered in a group to pregnant women in the morning prior to the commencement of the day's activities by the nurses and this may make some pregnant women who are late to miss the education session. Also, as pregnant women attend ANC, they are more likely to be screened for some of the danger signs of pregnancy including anaemia. In the Ho municipality, a majority (74.2\%) had done all the nine (9) Ghana health services recommended test for pregnancy. ${ }^{16}$ In Kiboga District in Uganda, pregnant women's knowledge on symptoms and negative consequences of anaemia were below average with only $45.1 \%$ of the respondents knowing at least 3 symptoms of anaemia. ${ }^{9}$ As blood transfusion will be a necessary intervention to safe life of pregnant women and baby, this practice should not be a routine intervention and should only be instituted when it is extremely necessary as preventive intervention measures fail. However, in Ghana, the practice of blood transfusion is generally widespread and in the Wassa East district, the practice can be described as a routine. It is worth noting that all pregnant women had an awareness of blood transfusion. Pregnant women who had no knowledge of the symptoms or effects of anaemia in pregnancy had put in measures towards receiving blood transfusion during delivery. Health care authorities need to put in measures to change this trend and institute instead preventive measures that reduce reliance of blood transfusion as a means to mitigate the effects of anaemia in pregnancy.

Of the 112 pregnant women who took part in the study $(41 \%)$ did not take medications such as iron and folic acid given at the antenatal clinic. These medications are supplements given to pregnant women to replenish and boost iron stocks especially in pregnancy and are supposed to be taken by every pregnant woman in Ghana. These findings are consistent with the results of other studies conducted in developing countries where anaemia still remains a major problem, pregnant women still do not consistently take advantage of the free iron supplementation given at the health facilities. Findings from a study conducted by Nasir et al, revealed that only about $44 \%$ of women in Pakistan take supplementary iron-folic acid despite the high prevalence of anaemia in the region. ${ }^{17}$ Anaemia was identified as a major problem among pregnant women in the district. The last recorded Haemoglobin level of pregnant women showed the following parameters; $\mathrm{Hgb}$ of less than 4 (12.5\%), 4.1 to $7.5(32.1 \%), 7.6$ to $11.0(43 \%)$ and more than 11.0 $(11.6 \%)$. This showed that majority $(88.4 \%)$ of the women are anaemic. Anaemia in pregnancy is considered severe when haemoglobin concentration is below $7 \mathrm{~g} / \mathrm{dl}$, moderate when it ranges between 7-9.9 g/dl and 10-11 g/dl representing mild anaemia. ${ }^{12}$ Data from the Ghana Demographic and Health Survey (2015) indicated that four out of every ten women, in their reproductive age in Ghana suffers from some form of anaemia. Findings from this study further revealed that $(28 \%)$ of pregnant women did not sleep under insecticide treated mosquito nets as $37 \%$ did not take malaria prophylaxis in pregnancy. In the findings from a related study community member did not understand the concept of prioritization of the ITN usage and used individual discretion and understanding as the yardstick. ${ }^{18} \mathrm{~A}$ cohort study in Burkina Faso concerning the use of bed nets to prevent malaria revealed that, the percentage of pregnant women who reported sleeping under the bed net the night before they were interviewed was $25 \%$. However, $50 \%$ of the women recalled sleeping under the net every night in the past week preceding the survey. ${ }^{19}$ The National Malaria Control Programme of Ghana advocates the prioritization of children under five years and pregnant women to sleep under insecticide treated net. The Ghana Health Service emphasizes that all citizens, including pregnant women, should sleep under insecticide treated bed nets, especially in rural malaria-endemic communities. This study further 
revealed that $37 \%$ of women do not take malaria prophylaxis during pregnancy. The malaria prophylaxis taken during pregnancy is expected to be taken under a directly observed system of administration where the drug is taken under the supervision of the health care provider.

There are several factors which may affect the attitude and perception of pregnant women on anaemia prevention in pregnancy. Lack of time $(44.5 \%)$ to attend ANC was a key factor identified in this study as a factor influencing attitude and perception of anaemia during pregnancy. This is affirmed in the findings of a study conducted by Chacko et al. Their findings revealed that women might not afford to spend much time in the antenatal clinic and therefore will prefer to carry the pregnancy without an antenatal visit. ${ }^{20}$ Some other factors identified from the data which affected antenatal visit were lack of knowledge on the importance of antenatal care $(18.8 \%)$, financial problems $(17.9 \%)$, and health facilities which are far from the residents of the respondents $(18.8 \%)$. Concerning nutritional practices of the pregnant women, it was realized that the major factor which contributed to non-adherence to professional nutritional advice was lack of money to buy foodstuffs $(45.5 \%)$. Due to economic constraints, most women will only eat what is available without seeking to take food according to professional advice. This finding is supported by the study conducted by Chang, Zeng, Brouwer, Kok and Yan, on maternal adherence to micronutrient supplementation before and during pregnancy in Northwest China. Their findings showed that higher income levels were associated with high adherence to micronutrient supplementation. ${ }^{21}$ Food taboos are known from almost every human society and prohibitions, usually are present in target groups such as menstruating females, pregnant women, lactating mothers and women in childbearing age. ${ }^{22}$ Diet restrictions through food taboos are common and may lead to further depletion of micronutrient stores in the body and this predispose pregnant women to anaemia. ${ }^{23}$ Cultural restrictions such as food taboos were however not applicable to the women in the Wassa East District. This deviation can be attributed to the fact that culture varies from community to community, and therefore not all cultures restrict the consumption of foods that promote blood production in the body. Other factors which affected the nutritional attitude of the respondents were the unavailability of foodstuffs and inadequate knowledge on the importance of eating a nutritious meal. Some respondents think that all that matters is satisfaction.

The results from the cross-tabulation showed that demographic characteristics such as educational level of respondents had a major impact on their knowledge on anaemia and their attitude toward anaemia prevention in pregnancy. Furthermore, there was a strong association between respondents' knowledge level and antenatal practices. Demographic characteristics such as ethnicity, religion, and age did not have any association with respondents' knowledge and attitude. This is collaborated in the study findings of Dickson (2016) where the level of education-secondary and tertiary-was significantly associated with knowledge on anaemia and attitude $(p=0.001) .{ }^{24}$ Women who have attained higher education have the capacity to access and understand information pertaining to anaemia, and other health issues, which could thus explain the observation made in this study. In addition, it has been shown by WHO (2016) that knowledge of a health subject translates into a positive attitude towards the topic. ${ }^{1}$ This substantiates this study findings that knowledge was associated with antenatal practices. It also justifies why women who were highly educated had a positive attitude towards anaemia and its prevention during pregnancy. Nonetheless, Dickson (2016) discovered that there was a significant association between respondents aged more than 30 years and knowledge on anaemia $(\mathrm{p}=0.001) .{ }^{24}$ This is inconsistent with this study findings, even though the age categorization in this study and that of Dickson (2016) differs. Okoh, Iyalla, Omunakwe, Iwo-Amah, and Nwabuko, (2016) neither found any association between age and knowledge on anaemia, nor age and attitude towards anaemia among pregnant women. ${ }^{25}$ The relative varying level of implementation of protective means and the general regard of blood transfusion as a de facto means of dealing with the anaemia in pregnancy in the district should still remain a health concern to policymakers and implementers.

\section{CONCLUSION}

This study showed that lack of knowledge on the importance of antenatal care and financial constraints were among some of the reasons leading to a surge in anaemia amongst pregnant women in the district. There is therefore the need for health care providers to incorporate services which enable pregnant women to walk in, and access valuable information on anaemia in pregnancy so as to improve their knowledge and attitude towards anaemia prevention. This will enhance the knowledge level of pregnant women on anaemia and effectively improve their practice while health care policies are implemented to ensure that the vulnerable populations directly benefit from enshrined health education on anaemia that is provided at the ANC clinic especially in low-income rural farming communities. The district health management team must also put in place measures to improve the services of the health facilities in the district by increasing access and user-friendly interventions for those who attend ANC. This will encourage pregnant women to attend ANC regularly as well as abide by the norms of a healthy pregnancy.

Funding: No funding sources

Conflict of interest: None declared

Ethical approval: The study was approved by the Institutional Ethics Committee 


\section{REFERENCES}

1. World Health Organization. Guideline: Iron supplementation in postpartum women, 2016. Available at: https://apps.who.int/iris/bitstream/ handle/10665/249242/9789241549585-eng.pdf.

Accessed on $4^{\text {th }}$ May 2018.

2. World Health Organization. International statistical classification of diseases and related health problems. World Health Organization; 2004:1.

3. World Health Organization. International statistical classification of diseases and related health problems: $10^{\text {th }}$ revision (ICD-10), 1992. Available at: http://www.who.int/classifications/apps/icd/icd.

Accessed on $28^{\text {th }}$ April 2018.

4. Okeke PU. Anaemia in pregnancy-is it a persisting public health problem in Porto Novo-Cape Verde? Res J Med Sci. 2011;5(4):193-9.

5. Ezugwu EC, Mbah BO, Chigbu CO, Onah HE. Anaemia in pregnancy: A public health problem in Enugu, South-east Nigeria. J Obstet Gynaecol. 2013;33(5):451-4.

6. Pasricha SR, Drakesmith H, Black J, Hipgrave D, Biggs BA. Control of iron deficiency anemia in lowand middle-income countries. Blood. The J Am Society Hematol. 2013;121(14):2607-17.

7. McLean E, Cogswell M, Egli I, Wojdyla D, De Benoist B. Worldwide prevalence of anaemia, WHO vitamin and mineral nutrition information system, 1993-2005. Pub Health Nutrit. 2009;12(4):444-54.

8. Msuya SE, Hussein TH, Uriyo J, Sam NE, StrayPedersen B. Anaemia among pregnant women in northern Tanzania: prevalence, risk factors and effect on perinatal outcomes. Tanzania J Health Res. 2011;13(1):33-9.

9. Mbule AM, Byaruhanga YB, Kabahenda M, Lubowa A. Determinants of anaemia among pregnant women in rural Uganda. 2013;13(2):2259.

10. M'cormack FA, Drolet JC. Assessment of anemia knowledge, attitudes and behaviors among pregnant women in Sierra Leone. Health Educator. 2012;44(2):9.

11. Kotey A. The Causes of Anaemia in Agogo, Ashanti Region, Ghana (Doctoral dissertation). 2012. Available at: http://dspace.knust.edu.gh/handle/ 123456789/5437. Accessed on $20^{\text {th }}$ March 2020.

12. Salhan S, Tripathi V, Singh R, Gaikwad HS. Evaluation of hematological parameters in partial exchange and packed cell transfusion in treatment of severe anemia in pregnancy. Anemia. 2012:2012.

13. Demographic G. Health Survey (GDHS) Ghana statistical service Accra, Ghana health service (GHS). Accra, Ghana The DHS Program ICF International Rockville, Maryland, USA. 2014.

14. Ghimire N, Pandey N. Knowledge and practice of mothers regarding the prevention of anemia during pregnancy, in teaching hospital, Kathmandu. J Chitwan Med College. 2013;3(3):14-7.
15. Dougul Regis M, Padmavathi R. A prospective clinico hematological study in 100 cases of Pancytopenia in a tertiary care teaching hospital. Int J Res Med Sci. 2019;7(7):2610.

16. Konlan KD, Kombat JM, Bapuah MA, Wuffele GM. The use of sulphadoxinepyrimethamine as a malaria prophylaxis for pregnant women in the Volta Regional Hospital. Int $\mathbf{J}$ Med Health Sci. 2018;7(4):182-8.

17. Nisar YB, Alam A, Aurangzeb B, Dibley MJ. Perceptions of antenatal iron-folic acid supplements in urban and rural Pakistan: a qualitative study. BMC Preg Childbirth. 2014;14(1):344.

18. Konlan KD, Kombat JM, Japiong M, Konlan KD. Perception of pregnant women on maternity care services at the Volta Regional Hospital, Ghana. Int J Comm Med Public Health. 2018;5(7):2699.

19. Pettifor A, Taylor E, Nku D, Duvall S, Tabala M, Meshnick S, Behets F. Bed net ownership, use and perceptions among women seeking antenatal care in Kinshasa, Democratic Republic of the Congo (DRC): opportunities for improved maternal and child health. BMC Public Health. 2008;8(1):331.

20. Chacko R, Premkumar U, Joseph M, James J, Prabha $\mathrm{S}$, Jacob MK, et al. Knowledge, Attitude and practices of anemia among pregnant women in a Government hospital. Indo Am J Pharmal Res. 2016;6(11):6988-92.

21. Chang S, Zeng L, Brouwer ID, Kok FJ, Yan H. Effect of iron deficiency anemia in pregnancy on child mental development in rural China. Pediatr. 2013;131(3):e755-63.

22. deBritoJúnior LC, Estácio AG. Food taboos in medicine: a hypothesis for pathophysiology regarding harmful food. Revista da Associação Médica Brasileira (English Edition). 2013;59(3):2136.

23. Arzoaquoi SK, Essuman EE, Gbagbo FY, Tenkorang EY, Soyiri I, Laar AK. Motivations for food prohibitions during pregnancy and their enforcement mechanisms in a rural Ghanaian district. J Ethnobiol Ethnomed. 2015;11(1):59.

24. Patience DI. Knowledge and Perception of Risk of Anaemia During Pregnancy among Pregnant Women in Ablekuma South (Doctoral dissertation, University of Ghana). 2016. Available at: http://ugspace.ug.edu.gh/handle/123456789/21512. Accessed on $10^{\text {th }}$ March 2020.

25. Okoh DA, Iyalla C, Omunakwe H, Iwo-Amah RS, Nwabuko C. A retrospective study of the prevalence of anaemia in pregnancy at booking in Niger Delta, Nigeria. J Obstet Gynaecol. 2016;36(5):594-7.

Cite this article as: Konlan KD, Amoah RM, Saah JA, Abdulai JA, Mohammed I, Konlan KD, et al. Knowledge of pregnant women on the factors that influence anaemia in pregnancy in a rural farming district of the Western Region of Ghana. Int J Reprod Contracept Obstet Gynecol 2020;9:2370-6. 